\title{
"Market efficiency of traditional stock market indices and social responsible indices: the role of sustainability reporting"
}

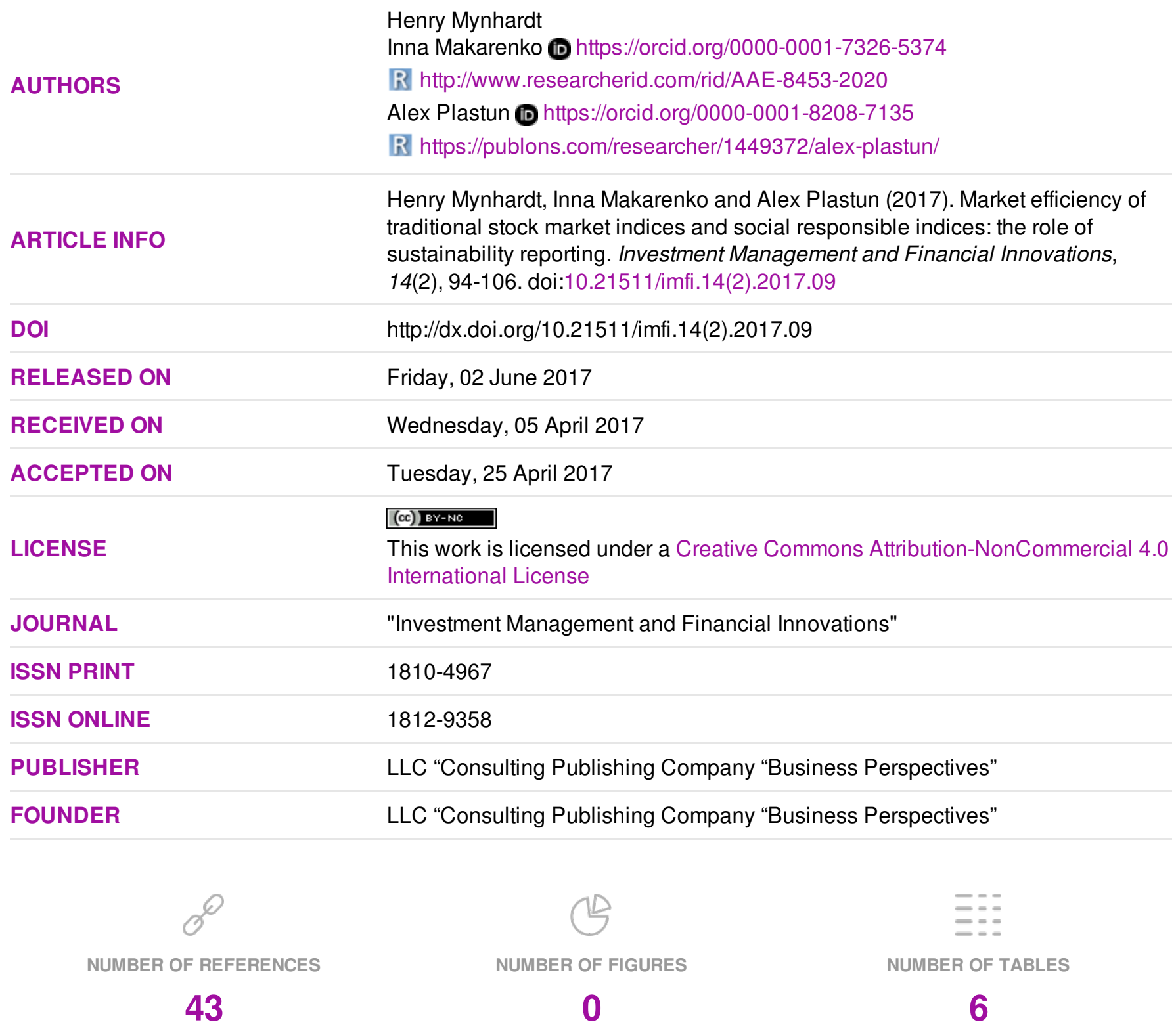

(C) The author(s) 2023. This publication is an open access article. 


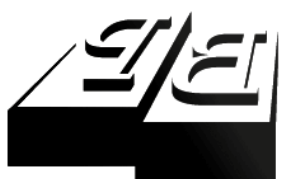

BUSINESS PERSPECTIVES

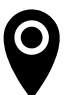

LLC "CPC "Business Perspectives" Hryhorii Skovoroda lane, 10, Sumy, 40022, Ukraine

www.businessperspectives.org

Received on: $5^{\text {th }}$ of April, 2017 Accepted on: $25^{\text {th }}$ of April, 2017

(C) Henry Mynhardt, Inna Makarenko, Alex Plastun, 2017

Henry Mynhardt, Southern Business School, South Africa.

Inna Makarenko, Sumy State University, Ukraine.

Alex Plastun, Sumy State University, Ukraine.
Henry Mynhardt (SouthAfrica), Inna Makarenko (Ukraine),

Alex Plastun (Ukraine)

MARKET EFFICIENCY

OF TRADITIONAL STOCK

MARKET INDICES AND SOCIAL

RESPONSIBLE INDICES:

\section{THE ROLE OF SUSTAINABILITY REPORTING}

\begin{abstract}
Corporate social responsibility, disclosed in sustainability reporting, influences the financial performance of companies. As a result, traditional stock market indices (TI) are expanded with the social responsible stock market indices (SRI). The aim of this study was to establish whether there are any differences in the behavior of the TI and SRI. To do this, the authors analyzed their efficiency. They used R/S analysis to calculate the Hurst exponent as a measure of persistence (long-term memory property). The presence of persistence was evidence in favor of less efficiency. According to empirical results, SRI has lower efficiency, in particular the Dow Jones Sustainability Index. Lower efficiency was also observed in the emerging markets with a responsible investment segment, compared to the traditional stock market indices. Further standardization and a common methodological approach to corporate sustainability reporting disclosure are proposed.
\end{abstract}

\section{Keywords \\ corporate social responsibility, sustainability reporting, long-term memory, social responsible indices, efficient market hypotheses (EMH)}

JEL Classification G02, G14, M41

\section{INTRODUCTION}

Sustainability reporting (SR) as the practice of measurement, disclosure, accountability, internal and external stakeholder's engagement in the activities of the organization in accordance with sustainable development goals (Goal 12.6) (Global Reporting Initiative, 2011) today is not just a popular trend - the scope of its distribution and perception of the largest companies in the world is quite impressive.

The KPMG study on corporate social responsibility (CSR) (KPMG, 2011, $2013,2015)$ showed that in 2011 , SR was presented by $64 \%$ of the top 100 companies from 41 countries, while in 2013 , it was $71 \%$ and in $2015,73 \%$.

Important question in this regard is SR consideration not only as a mirror of CSR and corporate strategy consistent with the sustainable development goals, but also as a basis for promoting models of responsible investment and a source of data for the ranking of companies in the social responsible stock market indices (SRI). 
SRI is opposed to traditional stock market indices (TI) through integrating CSR or criteria in the screening and selection of index constituents. These indices aggregate corporate key performance indicators on such criteria and give a picture of financial and sustainability performance of the leading part of companies (i.e., best in class).

The question is, therefore, whether the SRI, based on more transparent SR with ESG criteria, outperforms relevant TI. Furthermore, which implication do they have for market efficiency in terms of efficient market hypotheses (EMHs), as they are market benchmarks for the synthesized CSR and the performance of financial companies?

However, the relationship between CSR, SR and financial performance of companies in determining market indices is not unambiguous. Moreover, it is necessary to distinguish between the role of SR in ensuring the effectiveness of companies in TI measurements and SRI that have fundamentally different approaches to the incorporation of CSR. In particular, the inclusion of companies to the index basket TI, unlike SRI, accounts only for indicators of financial performance, not for attention to environmental and social indicators of $\mathrm{SR}$ of such companies and their efforts in CSR in general.

The aim of the present study was to explore the long-term memory properties of the TI and SRI (as a measure of market efficiency) and to provide some propositions for further development of the SR.

The practical implementation of research results is the substantiation of necessity of further development and standardization of SR as a basis for making traditional and responsible investment decisions and the efficiency of responsible investment practices as opposed to traditional financial strategies involving SRI and $\mathrm{TI}$, areas of regulation of developed financial markets and emerging markets, with SRI segments on the basis of EMH.

The special interest of the present study was to identify signs of long-term memory in TI and SRI indices, which allow data to differentiate these indices as for their effectiveness in terms of EMH, to ground SR value for constituent companies in these indices in achieving this performance and to extrapolate the findings on the efficiency of financial markets given their differentiation in terms of development (developed and emerging markets) and the allocation of pre-crisis, crisis and post-crisis periods.

The research results provided the rationale for further SR development and standardization as a basis for making traditional and responsible investment decisions, as well as some regulation issues on developed and emerging financial markets with responsible investment segments concerning market transparency and efficiency.

The study identified the signs of long-term memory in the TI and SRI, differentiated indices in terms of their performance, investigated the role of SR of companies, namely index constituents in facilitating their performance and extrapolating these findings on the efficiency of financial markets (developed and emerging markets in pre-crisis, crisis and post-crisis periods). These are: research methodology - R/S analysis and the Hurst exponent as a measure of persistence were never used to compare SRI and TI performance; analysis of market efficiency in the case of SRI and comparison with the traditional segment; analysis of market efficiency behavior in different conditions (pre-crisis, post-crisis and crisis periods) and the use of the latest data (till the end of 2016); exploring the role of SR in SRI and TI performance and how this influences the efficiency of the markets; further prospects for mandatory implementation of SR.

The remainder of the article is organized as follows: section 1 briefly reviews the literature on linkages between CSR, financial performance and effectiveness of TI and SRI. Section 2 contains tested hypotheses; section 3 outlines data and empirical methodology. Section 4 presents the empirical results. Finally, last section presents concluding remarks. 


\section{LITERATURE REVIEW}

Financial effectiveness of the market, detailed in traditional financial statements, is primarily reflected in its position in the index basket TI, while the financial effectiveness of companies that are aimed at achieving benchmarks for CSR and sustainable development criteria is embodied in SR (integrated reporting), reflected in its position in the SRI. In this regard, a measure of financial performance of the company, in contrast to existing approaches: return on equity (ROE), return on assets (ROA), share price and market capitalization), its incorporation and place in an appropriate market index, including SRI, can be considered.

In the context of the study, it is worth to focus on works studying the dynamics of SRI and TI as market benchmarks that represent the financial results of constituent companies (income, capitalization, earnings per share, etc.). See, in this regard, Hoti et al. (2008), Lopez et al. (2007), Lapinskiene (2011), Ameur and Senanedsch (2014), Albaity and Ahmad (2011), Statman (2000), Belghitar et al. (2014), Schröder (2007).

The study of the dynamics of TI and SRI is based on the results of the survey of modern index products of major information-analytical groups in the world. The defining feature of SRI, unlike traditional indices, is focused on adhering to sustainable development objectives by companies or constituents, which are translated into criteria disclosed in their corporate reporting during the implementation of screening and their portfolio of responsible investments or when the companies are included in the indices of sustainable development. According to the prescribed methodology, the best companies are included in SRI (best-in-class approach), which constitutes the basket TI demonstrating good financial results, but considering promulgated by such companies reporting on compliance with these criteria and CSR, excluding trade in weapons, alcohol, tobacco and other negative types of businesses.

For example, one of the indices of the Dow Jones Sustainability World Index (DJSI World) represents the financial effectiveness of $10 \%$ of the companies with the best achievements in the field of
CSR with 2,500 largest companies S\&P Global Broad Market Index representing 60 areas according to classification by RobecoSAM in 47 countries. The commonly used term ESG (environmental, social and governance) criteria was used for the first time in the Principles for Responsible Investment. Based on these ESG criteria, a total score is calculated for each company, which reflects the level of CSR, which, in turn, determines the weight of the company in the DJSI World index. The selected focus group of the research can be separated according to the results, illustrating the presence or absence of the relationship between efficiency of SRI and TI and disclosure of information according to the principles of sustainable development and CSR by the indices of companies or constituents.

Among the studies that confirm the positive nature of such connection, we can name: $\mathrm{Di}$ Bartolomeo and Kurtz (2012), Collison et al. (2008), Ameur and Senanedsch (2014), Belghitar et al. (2014). Unlike previous authors, Statman (2000, 2006), comparing the dynamics of SRI with the S\&P 500 index, found that the yield of SRI exceeded the S\&P 500, but results were not statistically significant. The lack of a significant difference between the TI and 29 SRI was also recorded by Schröder (2007) and Albaity and Ahmad (2011).

Managi et al. (2012) found that a statistically significant difference between the SRI and TI volatility was absent, and that incorporation of sustainable development criteria and disclosure of them is a sign of good corporate governance practices and the basis for responsible investment.

Neutrality in the relationship between the indices is shown in the work of Hoti et al. (2008), who noted the high level of correlation between TI and SRI. Lapinskiene (2011) notes that the difference between the TI and SRI exists due to the structural composition of indices.

From the standpoint of geographical structure of indices and, at the same time, the structure and level of development, the effectiveness of global markets in the regional context by Managi et al. (2012) should be noted. These researchers analyzed SRI and benchmarks for TI for the 
United States, the United Kingdom and Japan. Belghitar et al. (2014) considered such regions as the United States, the United Kingdom and Europe as a whole. Hayati, Sedaghat (2016) used data about efficiency of investment in companies listed at Tehran Stock Exchange. Velte (2016) investigates ESG criteria using data of German companies listed on the Prime Standard of the Frankfurt Stock Exchange (DAX30, TecDAX, MDAX, SDAX).

Cortez et al. (2009) show that SRI has a better performance on European markets than in the United States because of the style of responsible investing. With regard to the period of research, only a few works by Ameur and Senanedsch (2014) and Lapinskiene (2011) show a demarcation of a crisis period in the development of financial markets, which, however, seems fundamental in the study of TI and SRI from a standpoint of stability and efficiency of financial markets, on which different companies from the position of CSR and disclosure of information are present.

Despite the considerable amount of research on various aspects of the differences between the TI and SRI, there is one very important aspect today that remains unreviewed - their effectiveness and the nature of changes in the dynamics of indices (the presence in dynamics of long-term memory signs, in fact, it is about persistence). Efficiency is a key aspect when it comes to analysis of a market (asset), because its level determines not only the behavior of the prices of financial assets, but also provides information on the fundamental predictability of prices and the possibility of obtaining excessive profits from operations with financial assets. In this respect, previous studies on the evaluation of TI and SRI return seem to us to be studies of the effects, while the analysis of effectiveness relates rather to analysis of the reasons.

The phenomenon of persistency (long-term memory) is discussed particularly by Mandelbrot (1972) and Peters (1991, 1994). Analysis of persistency in the financial markets and their efficiency is provided by Los (2003), Greene and Fielitz (1977), Lo (1991), Cheung and Lai (1995), Jacobsen (1995), McKenzie (2001), Costa and Vasconcelos (2003), Los (2006), Onali and Goddard (2011).
Authors who place important focus on this work are Corazza and Malliaris (2002), Glenn (2007), Cajueiro and Tabak (005) and Grech and Pamula (2008), who emphasize the use of the Hurst exponent as a measure of long-term memory and efficiency of markets. It is, therefore, important to understand the way in which CSR and compliance to ESG criteria disclosed in corporate reporting of companies affect the behavior of stock prices of these companies and whether there exists such an effect at all. The results obtained may be useful in the first place to investors, because they let you understand whether investing in CSR-oriented business is more attractive and potentially more profitable than investments in conventional companies.

In summary, it can be mentioned that without exception, all works concerning proving or refuting the relationship between CSR, TI and SRI efficiency representing the financial performance of companies that are implemented in the appropriate weight of the company in the calculation of market index (TI or SRI) regardless of the level, timing, scope or methodology of study are based on the study of corporate reporting of companies with the focus on disclosure of information according to ESG criteria. This is, after all, the foundation of communication between mission and company strategy, goals of sustainable development, the financial performance of the company and its investment attractiveness in terms of responsible investing and informational efficiency of the market environment.

\section{FORMULATION OF HYPOTHESES}

The existence of such a large number of studies on the comparative nature of investment with the incorporation of sustainable development criteria and traditional investment indicates disputability and ambiguity of the role of CSR companies to obtain higher financial results.

At the same time, the proof or disproof of a view has implications not only for the development of responsible investment practices as such, but also for mechanisms for the disclosure of CSR, forming a single standardized approach to corporate 
SR representation and ensuring the efficiency of financial markets in general.

The study of the efficiency of the financial markets with the SRI segment in the analyzed works of scientists considers the key tenets of the efficient market hypothesis (EMH), which is a base of current traditional approaches to portfolio management. In terms of an EMH, responsible investment has substantial limitations in portfolio diversification. Therefore, the postulate that SRI does not exceed the TI means that investors wish to pay for accounting of preferences to achieve ESG criteria and are consistent with EMH arguments that the effectiveness of responsible investment should be lower than the traditional. However, other things being equal, when SRI demonstrates higher efficiency than their market benchmarks, such market situation should be classified as market anomalies.

Having analyzed the literature, the key areas that need improvement and additional research, in our opinion, are:

- selection of the array of TI and SRI covering not only the leading financial markets in different regions of the world (United States, Europe, Asia), but also the basic criteria of sustainable development and disclosure of information about it by companies or constituents of indices that meet the objectives of sustainable development better;

- formation of methodology of studied data from a position of confirming the feasibility of using EMH as a tool that explains the work of traditional financial markets and responsible investment markets, and establishing the relationship between disclosure of SR and efficiency of financial markets, in contrast to the array of studies that focus solely on financial efficiency of individual companies and funds; and

- extension of the study period - from the introduction of key SRI to today, and isolation from the perspective of the efficiency of financial markets of pre-crisis, crisis and post-crisis periods in terms of geographical regions by developed financial markets and emerging markets.
Tested hypotheses can be presented as follows:

- Efficiency of traditional markets and markets with responsible investment segment differs:

H1: Are there any long-term memory properties in the SRI and TI time series, i.e., are they efficient in terms of EMH or not?

- Sustainability reporting issue:

H2: Does the company, presented in SRI, disclose more transparent information on CSR in SR, giving investors an opportunity to make better-grounded decisions? Is the SRI outperformed by TI in this regard?

- Technical aspects:

H3: Are financial markets (both responsible and traditional) of developed countries more efficient than markets in developing countries due to better disclosure on ESG criteria by the companies or index constituents?

H4: Do the levels of SRI and TI market efficiency differ during the crisis, in contrast to before the crisis and after the crisis in the context of developed markets and emerging markets?

\section{DATA AND METHODOLOGY}

Selection of TI and SRI (Table 1) was carried out keeping the following aspects in mind:

- a recognized status on the financial markets and the markets of responsible investment;

- the inclusion of reputable investor index groups that automatically displays the disclosure of CSR reporting by the world's largest companies that make up the index;

- focusing on the criteria of sustainable development (disclosure of the reporting of key indicators in environmental, social, administrative (economic) dimensions);

- consideration of the efficiency level of financial markets in different regions of the world and the level of market development. 
Table 1. Indices of sustainable development and the corresponding financial indices studied by the authors

\begin{tabular}{|c|c|c|c|c|c|c|}
\hline Index & Group & Year & Areas & $\begin{array}{l}\text { Focus on } \\
\text { sustainability } \\
\text { criteria }\end{array}$ & $\begin{array}{c}\text { Traditional } \\
\text { index }\end{array}$ & Regional aspect \\
\hline $\begin{array}{l}\text { Dow Jones } \\
\text { Sustainability } \\
\text { Indices (DJSI) }\end{array}$ & $\begin{array}{l}\text { Dow Jones } \\
\text { Indices, } \\
\text { STOXX } \\
\text { Limited and } \\
\text { the SAM } \\
\text { group }\end{array}$ & 1998 & $\begin{array}{l}60 \\
\text { industry } \\
\text { groups } \\
\text { and } 18 \\
\text { market } \\
\text { sectors }\end{array}$ & $\begin{array}{l}\text { ESG, excluding } \\
\text { companies } \\
\text { that generate } \\
\text { revenue from } \\
\text { tobacco, gambling, } \\
\text { armaments or } \\
\text { firearms, and } \\
\text { alcohol }\end{array}$ & DJIA & $\begin{array}{l}\text { DJSI World } \\
\text { DJSI World ex all } \\
\text { DJSI World Enlarged } \\
\text { DJSI World Enlarged ex all } \\
\text { ex AE } \\
\text { DJSI Europe } \\
\text { DJSI U.S. } \\
\text { DJSI North America } \\
\text { Dow Jones Sustainability } \\
\text { Emerging Markets } \\
\text { Diversified, etc. }\end{array}$ \\
\hline $\begin{array}{l}\text { S \& P } 500 \\
\text { Environmental } \\
\text { \& Socially } \\
\text { Responsible } \\
\text { Index }\end{array}$ & $\begin{array}{l}S \& P, S A M \\
\text { group }\end{array}$ & 2010 & $\begin{array}{l}59 \\
\text { industry } \\
\text { groups } \\
\text { and } 11 \\
\text { market } \\
\text { sectors. }\end{array}$ & $\begin{array}{l}\text { ESG, excluding } \\
\text { companies that } \\
\text { generate revenue } \\
\text { from fossil fuels, } \\
\text { tobacco and military } \\
\text { equipment, etc. }\end{array}$ & S\&P 500 & $\begin{array}{l}\text { S\&P } 500 \text { ESG Index } \\
\text { S\&P Europe } 350 \text { ESG Index, } \\
\text { etc. } \\
\text { S\&P Global } 1200 \text { ESG } \\
\text { Index } \\
\text { S\&P Global } 1200 \text { Climate } \\
\text { Change Low Volatility High } \\
\text { Dividend (EUR), etc. }\end{array}$ \\
\hline $\begin{array}{l}\text { FTSE4Good } \\
\text { Global Index }\end{array}$ & FTSE Russell & 2001 & $\begin{array}{l}19 \text { market } \\
\text { sectors }\end{array}$ & ESG & FTSE 100 & $\begin{array}{l}\text { FTSE4Good US } \\
\text { FTSE4Good Global } 100 \\
\text { FTSE4Good Europe } 50\end{array}$ \\
\hline $\begin{array}{l}\text { MSCI World ESG } \\
\text { Index }\end{array}$ & MSCI Barra & 2010 & $\begin{array}{l}11 \text { market } \\
\text { sectors }\end{array}$ & $\begin{array}{l}\text { ESG, excluding } \\
\text { companies that } \\
\text { generate revenue } \\
\text { from alcohol, } \\
\text { tobacco, gambling }\end{array}$ & $\mathrm{MSCl}$ & $\begin{array}{l}\text { MSCI USA ESG } \\
\text { MSCI EAFE ESG, etc. }\end{array}$ \\
\hline $\begin{array}{l}\text { NASDAQ OMX } \\
\text { CRD Global } \\
\text { Sustainability } \\
\text { Index }\end{array}$ & $\begin{array}{l}\text { NASDAQ } \\
\text { OMX Group, } \\
\text { Inc. CRD } \\
\text { Analytics }\end{array}$ & 2009 & $\begin{array}{l}11 \text { market } \\
\text { sectors }\end{array}$ & $\begin{array}{l}\text { Financial, } \\
\text { environmental and } \\
\text { social performance } \\
\text { indicators }\end{array}$ & $\begin{array}{l}\text { NASDAQ } \\
\text { Composite }\end{array}$ & $\begin{array}{l}\text { NASDAQ OMX CRD } \\
\text { Global Sustainability } 50\end{array}$ \\
\hline
\end{tabular}

We used daily data for the indices presented in the Table 1. The sample period differs for the different indices because of data availability. Some indices are older (DJSI World), while other ones are younger (MSCI EAFE ESG or NASDAQ OMX CRD Global Sustainability 50). The data period ranges from the date of index birth until the end of 2016. In case of traditional indices (DJIS \& P500, etc.), the data period covers 2000-2016.

In order to explore the behavior of the sustainability indices and their traditional analogues during the crisis, we divide data sets in three sub-periods: 2004-2006 (pre-crisis), 2007-2009 (crisis), 2010-2012 (post-crisis).

To measure the level of efficiency, we used the Hurst exponent. According to results by Mynhardt et al. (2014), the most appropriate method of the Hurst exponent calculation for the financial data is $\mathrm{R} / \mathrm{S}$ analysis. This was developed by Hurst (1951) and improved by Mandelbrot (1972), Peters (1991, 1994) and others for analysis of the financial markets. 
The algorithm of $\mathrm{R} / \mathrm{S}$ analysis used in this article is presented below:

1. A time series of length $M$ transforms into one of length $N=M-1$ using logs and converting prices into returns:

$$
N_{i}=\log \left(\frac{Y_{t+1}}{Y_{t}}\right), \quad t=1,2,3, \ldots(M-1)
$$

This period is divided into contiguous $A$ subperiods with length $n$, so that $A_{n}=N$. Then, we identified each sub-period as $I_{a}$, given the fact that $a=1,2,3 \ldots, A$. Each element $I_{a}$ is represented as $N_{k}$ with $k=1,2,3 \ldots, N$. For each $I_{a}$ with length $n$, the average and $e_{a}$ is defined as:

$$
e_{a}=\frac{1}{n} \sum_{k=1}^{n} N_{k, a}
$$

$k=1,2,3, \ldots N$,

$a=1,2,3, \ldots A$

2. Accumulated deviations $X_{k, a}$ from the average $e_{a}$ for each sub-period $I_{a}$ are defined as:

$$
X_{k, a}=\sum_{i=1}^{k}\left(N_{i, a}-e_{a}\right)
$$

The range is defined as the maximum index $X_{k, a}$ minus the minimum $X_{k, a}$, within each sub-peri$\operatorname{od}\left(I_{a}\right)$ :

$$
R_{I_{a}}=\max \left(X_{k, a}\right)-\min \left(X_{k, a}\right),
$$

$1 \leq k \leq n$.

3. The standard deviation $S_{I_{a}}$ is calculated for each sub-period $I_{a}$ :

$$
S_{I_{a}}=\left(\frac{1}{n} \sum_{k=1}^{n}\left(N_{k, a}-e_{a}\right)^{2}\right)^{0.5} .
$$

4. Each range $R_{I_{a}}$ is normalised by dividing by the corresponding $S_{I_{a}}$. Therefore, the re- normalized scale during each sub-period $I_{a}$ is $R_{I_{a}} / S_{I_{a}}$. In step 2 above, we obtained adjacent sub-periods of length $n$. Thus, the average $R / S$ for length $n$ is defined as:

$$
\left(\frac{R}{S}\right)_{n}=\frac{1}{A} \sum_{i=1}^{A} \frac{R_{I_{a}}}{S_{I_{-}}}
$$

5. The length $n$ is increased to the next higher level, $(\mathrm{M}-1) / n$, and must be an integer number. In this case, we use $n$-indices that include the initial and ending points of the time series, and Steps 1-6 are repeated until $n=(M-1) / 2$.

6. The least square is used to estimate the equation $\log (R / S)=\log (c)+H \log (n)$. The angle of the regression line is an estimate of the Hurst exponent $H$. The Hurst exponent $H$ changes over the interval $[0,1]$.

Based on the values of the Hurst exponent, the data can be classified as follows:

- $0 \leq H<0.5$ - the EMH is not confirmed, the distribution has fat tails, the series are antipersistent and returns are negatively correlated;

- $H=0.5$ - the EMH is confirmed, the data are random, asset prices follow a random Brownian motion (Wiener process), the series are normally distributed, returns are uncorrelated (no memory in the series), they are a white noise, traders cannot 'beat' the market using any trading strategy;

- $0.5<H \leq 1$ - the EMH is not confirmed, the distribution has fat tails, the series are persistent, returns are positively correlated, and there is a trend in the market. 


\section{EMPIRICAL RESULTS}

Overall results of the Hurst exponent calculations for the Dow Jones Sustainability Indices and traditional Dow Jones Industrial Index are presented in Table 2.

As can be seen, in many cases, the Dow Jones Sustainability Indices show signs of anti-persistence in data (returns are negatively correlated) and their efficiency is low. At the same time, traditional the Dow Jones Industrial Index is close to 0.5 , which is evidence in favor of market efficiency. In general, results show that the use of sustainability indices makes markets less efficient. The biggest deviations from the efficiency are observed in the emerging markets. This confirms the common belief that developing markets are less efficient than developed ones.

As for the practical implications of these results, it should be mentioned that dynamics of sustainability indices is much more predictable than the traditional Dow Jones Industrial Index (whose dynamics is close to the random). It gives opportunities for extra profit generations from trading operations with sustainability indices.

Overall results of the Hurst exponent calculations for the S\&P 500 Environmental \& Socially Responsible Index and traditional S\&P500 Index are presented in Table 3.

Table 2. Overall results of the Hurst exponent calculations for the Dow Jones Sustainability Indices and traditional Dow Jones Industrial Index *

\begin{tabular}{|c|c|c|}
\hline Index & Hurst exponent & Conclusions \\
\hline DJI & 0.51 & Market is efficient. No persistence in data. \\
\hline DJSI World & 0.33 & Market is not efficient. Data are anti-persistent. \\
\hline DJSI World ex all & 0.42 & Market is not efficient. Data are anti-persistent. \\
\hline DJSI World Enlarged & 0.29 & Market is not efficient. Data are anti-persistent. \\
\hline DJSI World Enlarged ex all ex AE & 0.37 & Market is not efficient. Data are anti-persistent. \\
\hline DJSI Europe & 0.55 & Market is close to be efficient. Signs of persistence in data. \\
\hline DJSI U.S. & 0.54 & Market is close to be efficient. Signs of persistence in data. \\
\hline DJSI North America & 0.55 & Market is close to be efficient. Signs of persistence in data. \\
\hline $\begin{array}{l}\text { Dow Jones Sustainability Emerging } \\
\text { Markets Diversified }\end{array}$ & 0.34 & Market is not efficient. Data are anti-persistent. \\
\hline $\begin{array}{l}\text { Dow Jones Sustainability Asia/Pacific } \\
\text { Developed Diversified }\end{array}$ & 0.52 & Market is efficient. No persistence in data. \\
\hline DJSI Emerging Markets & 0.36 & Market is not efficient. Data are anti-persistent. \\
\hline
\end{tabular}

Table 3. Overall results of the Hurst exponent calculations for the S\&P500 Environmental \& Socially Responsible Index and traditional S\&P500 Index *

\begin{tabular}{|c|c|c|}
\hline Index & Hurst exponent & Conclusions \\
\hline S\&P 500 Index & 0.48 & Market is efficient. No persistence in data \\
\hline S\&P500 ESG Index & 0.52 & Market is efficient. No persistence in data \\
\hline S\&P Europe 350 ESG Index & 0.53 & Market is efficient. No persistence in data \\
\hline S\&P Global 1200 ESG Index & 0.54 & Market is close to be efficient. Signs of persistence in data \\
\hline $\begin{array}{l}\text { S\&P Global } 1200 \text { Climate Change Low } \\
\text { Volatility High Dividend (EUR) Dynamic } \\
\text { Rebalancing Risk Control 10\% Total } \\
\text { Return Index }\end{array}$ & 0.56 & Market is close to be efficient. Signs of persistence in data \\
\hline $\begin{array}{l}\text { S\&P Global } 1200 \text { Climate Change Low } \\
\text { Volatility High Dividend Index }\end{array}$ & 0.56 & Market is close to be efficient. Signs of persistence in data \\
\hline S\&P/TOPIX 150 ESG Index & 0.55 & Market is close to be efficient. Signs of persistence in data \\
\hline
\end{tabular}

Note: ${ }^{*}$ for explanations of the periods of analysis, see explanations in section 3 above. 
In general, differences between the S\&P 500 Environmental \& Socially Responsible Index and the traditional S\&P 500 Index are not very significant and may be caused by the differences in periods of analysis and length of data sets. Still, results for the S\&P Global 1200 Climate Change Indices look different, especially from the traditional S\&P 500 Index. They might be treated as evidence of changes in the level of market efficiency and less efficiency of the ESG Indices. This confirms results from the Dow Jones Sustainability Indices analysis. However, in the case of S \& P 500 ESG Indices, data are persistent (returns are positively correlated). General conclusion is close to that from the Dow Jones Sustainability Indices analysis: sustainability indices are less efficient and look more predictable then traditional indices.

Overall results of the Hurst exponent calculations for the FTSE4Good Global Index and traditional FTSE 100 Index are presented in Table 4.
As can be seen, in many cases, results of the sustainability indices are even more efficient than those of the traditional FTSE 100 Index. Still, there are some exceptions. For example, FTSE4Good Bursa Malaysia looks quite inefficient with signs of persistence (returns are positively correlated). This confirms previous results and common belief that emerging markets are less efficient.

Overall results of the Hurst exponent calculations for the MSCI World ESG Index, NASDAQ OMX CRD Global Sustainability Index and their traditional analogues (MSCI Index and NASDAQ Composite Index) are presented in Table 5.

Results of the MSCI ESG Indices and traditional MSCI Index are very close to each other and small differences can be explained by the measurement errors. As for the NASDAQ Sustainability Index, it appears to be more efficient than traditional analogue. Still, difference is not sufficient and can be explained by the different periods of analysis.

Table 4. Overall results of the Hurst exponent calculations for the FTSE4Good Global Index and traditional FTSE 100 Index *

\begin{tabular}{|c|c|c|}
\hline Index & Hurst exponent & Conclusions \\
\hline FTSE 100 Index & 0.46 & $\begin{array}{l}\text { Market is close to be efficient. Signs of anti- } \\
\text { persistence in data. }\end{array}$ \\
\hline FTSE4Good US & 0.50 & Market is efficient. No persistence in data. \\
\hline FTSE4Good Global 100 & 0.50 & Market is efficient. No persistence in data. \\
\hline FTSE4Good Europe 50 & 0.48 & Market is efficient. No persistence in data. \\
\hline FTSE4Good Japan & 0.55 & $\begin{array}{l}\text { Market is close to be efficient. Signs of persistence } \\
\text { in data. }\end{array}$ \\
\hline FTSE4Good Bursa Malaysia & 0.61 & Market is not efficient. Data are persistent. \\
\hline FTSE4Good Environmental Leaders Europe 40 & 0.49 & Market is efficient. No persistence in data. \\
\hline
\end{tabular}

Note: ${ }^{*}$ for explanations of the periods of analysis, see section 3 above.

Table 5. Overall results of the Hurst exponent calculations for the MSCI ESG Indices, NASDAQ OMX CRD Global Sustainability Index and their traditional analogues (MSCI Index and NASDAQ Composite Index)*

\begin{tabular}{l|c|c}
\hline \multicolumn{1}{c}{ Index } & Hurst exponent & Conclusions \\
\hline MSCI Index & 0.51 & Market is efficient. No persistence in data. \\
MSCI USA ESG & 0.52 & Market is efficient. No persistence in data. \\
MSCI EAFE ESG & 0.48 & Market is efficient. No persistence in data. \\
\hline NASDAQ Composite Index & 0.55 & Market is not efficient. Data are persistent. \\
NASDAQ OMX CRD Global Sustainability 50 & 0.52 & Market is efficient. No persistence in data. \\
\hline
\end{tabular}

Note: ${ }^{\star}$ for explanations of the periods of analysis, see section 3 above. 
Summarizing results for the sustainability indices analysis, we may conclude that they are mixed and rather unstable. Some regularities are detected. First, comparing with the traditional analogues, sustainability indices are less efficient. Second, emerging markets are less efficient than developed ones. Third, less efficiency makes investing in sustainability indices (especially for the emerging markets) more attractive, because they seem more predictable.

Behavior of sustainability and traditional indices during last financial crisis is provided for the following periods: pre-crisis, crisis and post-crisis periods. Results are presented in Table 6 .

As can be seen, financial crisis makes markets less efficient, and the use of sustainability indices cannot insure against this. At the same time, it should be noted that post- and pre-crisis periods are characterized by high levels of efficiency (for most of the cases). These results are in line with the previous results (for example, Mynhardt et al., 2014; and Caporale et al., 2016) which provide evidence of changes in market efficiency in time and especially during crisis periods.

In the context of the hypotheses developed, the findings can be grouped as follows: H1, namely Is there no long-term memory in time series, indices SRI and corresponding TI, i.e., whether they are effective in terms of EMH, was proved to TI and refuted for SRI, as for most of the analyzed $\mathrm{TI}$, the Hurst exponent value was close to 0.5, and, hence, the corresponding indices were effective. The level of information asymmetry in markets of responsible investment in this connection is higher, while the transparency of reporting of companies or constituents of SRI given the postulates of EMH was lower, because most SRI had signs of antipersistence, as well as persistent rows (depending on the market). Thus, in terms of the effect of CSR and SR of companies or constituents on the efficiency of SRI and TI, it should be noted that the findings could be attributed to the array of literature that established a negative relationship between these variables. We see the reasons for the negative effect of CSR on the effectiveness of indices in rising costs of collection, compilation, disclosure, publication and verification of information according to ESG criteria in comparison with the members of TI of companies that do not have these additional costs.

Regarding the accounting aspect and confirmation of hypothesis $\mathrm{H} 2$, namely Do the companies included in the SRI disclose broader and more transparent information on CSR in corporate reporting on sustainable development, giving investors an opportunity to make better and informed decisions that will be implemented in a more effective SRI than TI, it must be noted that this hypothesis should be rejected due to a lack of effectiveness of SRI compared to TI.

Table 6. Behavior of sustainability and traditional indices during pre-crisis, crisis and post-crisis periods: case of global financial crisis

\begin{tabular}{|c|c|c|c|}
\hline Index & $\begin{array}{c}\text { Pre-crisis } \\
(2004-2006)\end{array}$ & $\begin{array}{c}\text { Crisis } \\
(2007-2009)\end{array}$ & $\begin{array}{c}\text { Post-crisis } \\
(2010-2012)\end{array}$ \\
\hline DJI & 0.54 & 0.56 & 0.51 \\
\hline DJSI World & 0.38 & 0.17 & 0.22 \\
\hline DJSI U.S. & 0.54 & 0.55 & 0.5 \\
\hline DJSI Europe & 0.53 & 0.56 & 0.5 \\
\hline DJSI North America & 0.52 & 0.56 & 0.5 \\
\hline SP 500 & 0.52 & 0.55 & 0.51 \\
\hline FTSE & 0.5 & 0.53 & 0.51 \\
\hline $\mathrm{MSCl}$ & no data available & 0.55 & 0.51 \\
\hline MSCI USA ESG & 0.51 & 0.56 & 0.54 \\
\hline NASDAQ Composite & 0.57 & 0.57 & 0.53 \\
\hline
\end{tabular}


This means that the practice of disclosure on ESG criteria and submission SR is insuffficient, SR is vital to justify better investment decisions only to a specific group of stakeholders, including those that can take advantage of greater predictability of SRI due to the presence in their dynamics of long-term memory signs. Another problematic aspect that may explain this result of the hypothesis is spreading among reporting companies of socalled practice of 'green camouflage', i.e., disproportionate and narrowed disclosure of CSR and achievement of sustainable development.

The hypotheses regarding the technical aspects of the study, H3, namely Are financial markets (both responsible and traditional) of developed countries more efficient than markets in developing countries due to better disclosure on ESG criteria by the companies or index constituents? and $\mathrm{H} 4$, namely Do the levels of SRI and TI market efficiency differ during the crisis, in contrast to before the crisis and after the crisis in the context of developed and emerging markets? have been confirmed in the study.

This leads to two main conclusions: despite the higher efficiency of TI in terms of EMH, the effect of the crisis regarding these markets, and not only SRI markets, which have a smaller scale and greater volatility, was also notable. This confirms the need for early prediction of crises in these markets and coordination of efforts to make them more transparent.

The following conclusion concerns the need for better control and reduction of information asymmetry in emerging markets, including the segments of responsible investment, as compared to developed markets.

In our view, low efficiency of SRI in terms of EMH compared to TI in addition to traditional causes of higher value of initiatives on CSR and additional costs for reporting on sustainable development can also be explained by the absence of standardized approaches to its preparation and verification. These results can also be confirmed by the research by Gray (2006) who determined falsity in the absolute interdependent and complementary link between CSR, financial performance and the voluntary reporting of sustainable development, which does not fully comply with the concept of 'sustainable development' and points to the need for mandatory regulation of the compilation of such statements.

\section{CONCLUSION}

In theory, sustainability indices should be more efficient than traditional indices, because they claim to be the best of the breed. Still, according to the results of our research, the situation is controversial. Sustainability indices are less efficient than their traditional analogues (in most of the cases).

As additional results of this research, the following can be mentioned. Further evidence that emerging markets are less efficient than developed ones has been found. Less efficiency of the sustainability indices makes investing in companies with a high level of social responsibility (especially in the emerging markets) more attractive compared to traditional investment, because the presence of persistence in price returns makes them more predictable.

Furthermore, previous observations were confirmed that during a financial crisis, markets become less efficient. This is true for both the sustainability indices and traditional stock market indices.

The proof of the hypotheses about the negative effect of CSR disclosed in SR of companies or constituents of SRI on their financial efficiency, which is embodied in a lower efficiency of SRI compared to TI in terms of EMH, was based on the fact that responsible companies have higher costs of disclosure on ESG and its verification criteria than companies or constituents of TI.

The main reason for that hypothesis describing an accounting aspect of this study not being performed and lower SRI efficiency compared to TI being confirmed was the fact that the practice of reporting on sustainable development does not have a sufficient level of investors. 
Standardization and verification of corporate SR and its transparency, the disclosure of the significant aspects of the activity of companies were seen by us as the basis for its relevance, clarity and accuracy as key quality characteristics for making investment decisions. The proof of the technical hypotheses on the effectiveness of TI and SRI in terms of crisis and development of countries makes it possible to conclude about the fixation of the effect of the crisis of 2007-2009 in all markets and differentiation in terms of development into the markets of developed countries (more efficient in terms of EMH) and emerging markets (less efficient).

Further development is needed for investigating the prospects and problematic areas of SR and integrated reporting, reasons for their standardization all over the world.

\section{REFERENCES}

1. Albaity, M., \& Ahmad, R. (2011). Return performance and leverage effect in Islamic and socially responsible stock indices evidence from Dow Jones (DJ) and Financial Times Stock Exchange (FTSE). African Journal of Business Management, 5(16), 6927-6939.

2. Ameur, H. B., \& Senanedsch, J. (2014). Socially responsible investments: An international empirical study of time-varying risk premiums. Journal of Applied Business Research, 30(5), 1513-1523.

3. Belghitar, Y., Ephraim, C., \& Nitin, D. (2014). Does it pay to be ethical? Evidence from the FTSE4Good. Journal of Banking and Finance, 47(C), 54-62.

4. Cajueiro, D., \& Tabak, B. (2005) Ranking efficiency for emerging equity markets II. Chaos Solitons Fractals, 23, 671-675.

5. Caporale, G. M., Gil-Alana, L., Plastun, A., \& Makarenko, I. (2016). Long memory in the Ukrainian stock market and financial crises. Journal of Economics and Finance, 40(2), 235-257.

6. Cheung, Y., \& Lai, K. (1993). Do gold market returns have longrange dependence? The Financial Review, 28(2), 181-202.

7. Cheung, Y. W., Lai, K. S. (1995). A search for long-range dependence in international stock market returns. Journal of International Money and Finance, 14(4), 597-615.

8. Collison, D., Cobb, G., Power, D., \& Stevenson, L. (2009). FTSE4Good: Exploring its implications for corporate conduct. Accounting, Auditing \& Accountability Journal, 22(1), 35-58.

9. Corazza, M., \& Malliaris, A. (2002). Multifractality in foreign currency markets. Multinational Finance Journal, 6, 387-401.

10. Cortez, M., Silva, F., \& Areal, N. (2009). Socially responsible investing in the global market: The performance of US and European funds. Retrieved from https://ssrn. com/abstract $=1342469$

11. Costa, R. L., Vasconcelos, G. L. (2003). Long-range correlations and nonstationarity in the Brazilian stock market. Physica A, 329, 231-248.

12. Di Bartolomeo, D., \& Kurtz, L. (2012). The long-term performance of a social investment universe. The Journal of Investing, 20(3), 95-102.

13. Friedman, M. (1970, September 13). The social responsibility of business is to increase its profits. New York Times Magazine, 32-33.

14. Glenn, L. A. (2007). On randomness and the NASDAQ composite. Working paper. Retrieved from http://ssrn.com/ abstract $=1124991$

15. Global Reporting Initiative (2011). Sustainability reporting guidelines. Retrieved from https:// www.globalreporting.org/.../ G3.1-Guidelines-Incl-TechnicalProtocol.pdf
16. Gray, R. (2006). Does sustainability reporting improve corporate behaviour? Wrong question? Right time? Accounting and Business Research, 36, Suppl. $1,65-88$.

17. Grech, D., \& Pamula, G. (2008). The local Hurst exponent of the financial time series in the vicinity of crashes on the Polish stock exchange market. Physica A, 387(16/17), 4299-4308.

18. Greene, M. T., \& Fielitz, B. D. (1977). Long-term dependence in common stock returns. Journal of Financial Economy, 4, 339-349.

19. Hayati, K., Sedaghat P. (2016). An evaluation of the links between quality of reporting and efficiency of investment in companies listed at Tehran Stock Exchange. Problems and Perspectives in Management, 14(2(spec. issue)), 341-347.

20. Hoti, S., McAleer, M., \& Pauwels, L. L. (2008). Multivariate volatility in environmental finance. Mathematics and Computers in Simulation, 78(2), 189-199.

21. Jacobsen, B. (1995). Are stock returns long-term dependent? Some empirical evidence. Journal of International Financial Markets. Institutions and Money, 5(2/3), 37-52.

22. KPMG. (2011). The KPMG Survey of Corporate Responsibility Reporting 2011. Retrieved from http://www.csr.ee/wp-content/uploads/2016/03/KPMHG-International-Survey-of-CSR-2011.pdf 
23. KPMG. (2013). The KPMG Survey of Corporate Responsibility Reporting 2013. Retrieved from https:// assets.kpmg.com/content/dam/ kpmg/pdf/2015/08/kpmg-survey-of-corporate-responsibility-reporting-2013.pdf

24. KPMG. (2015). Survey of Corporate Responsibility Reporting 2015. Retrieved from https:// home.kpmg.com/au/en/home/insights/2015/11/corporate-responsibility-reporting-survey-2015. html

25. Lapinskiene, G. (2011). Sustainable enterprises: Responses of market values. Business Systems and Economics, 1(1), 71-83.

26. Lo, A. W. (1991). Long-term memory in stock market prices. Econometrica, 59, 1279-1313.

27. Lopez, M. V., Garcia, A., \& Rodriguez, L. (2007). Sustainable development and corporate performance: A study based on the Dow Jones Sustainability Index. Journal of Business Ethics, 75(3), 285-300.

28. Los, C. (2003). Financial market risk: Measurement and analysis. Routledge International Studies in Money and Banking, Vol. 24. London: Taylor and Francis.

29. Los, C., Yalamova, R. M. (2006) Multi-Fractal Spectral Analysis of the 1987 Stock Market Crash. International Research Journal of Finance and Economics, 1(4), 106-133.
30. Managi, S., Okimoto, T., \& Matsuda, A. (2012). Do socially responsible investment indexes outperform conventional indexes? Applied Financial Economics, 22(18), 1511-1527.

31. Mandelbrot, B. (1972). Statistical methodology for nonperiodic cycles: From the covariance to R/S analysis. Annals of Economic and Social Measurement, 1, 259-290.

32. Murray, A., Sinclair, C. D., Power, D., \& Gray, R. (2006). Do financial markets care about social and environmental disclosure? Further evidence and exploration from the UK. Accounting, Auditing and Accountability Journal, 19(2), 228-255.

33. Mynhardt, R. H., Plastun, A., \& Makarenko, I. (2014). Behavior of financial markets efficiency during the financial market crisis: 2007-2009. Corporate Ownership and Control, 11(2), 473-488.

34. OECD. (2014). The Evolution of Corporate Reporting for Integrated Performance Retrieved from https://www.oecd.org/sd-roundtable/papersandpublications/ The $\% 20$ Evolution $\% 20$ of $\% 20$ Corporate $\% 20$ Reporting $\% 20$ for $\% 20$ Integrated\%20Performance.pdf

35. Onali, E., \& Goddard, J. (2011). Are European equity markets efficient? New evidence from fractal analysis. International Review of Financial Analysis, 20(2), 59-67.
36. Opler, T. C., \& Sokobin, J. (1995). Does coordinated institutional activism work. Dice Center For Research In Financial Economics, Working Papers Series 95-5. Retrieved from SSRN: https://ssrn. com/abstract $=46880$

37. Peters, E. E. (1991). Chaos and order in the capital markets: A new view of cycles, prices, and market volatility. New York, NY: Wiley.

38. Peters, E. E. (1994). Fractal market analysis: Applying chaos theory to investment and economics. New York, NY: Wiley.

39. Schröder, M. (2007). Is there a difference? The performance characteristics of SRI equity indices. Journal of Business Finance and Accounting, 34(1/2), 331-348.

40. Smit, A. M., Zyl, J. (2016) Investigating the extent of sustainability reporting in the banking industry. Banks and Bank Systems, 11(4), 71-81.

41. Statman, M. (2000, May/June). Socially responsible mutual funds. Financial Analysts Journal, 30-39.

42. Statman, M., \& Glushkov, D. (2008). The wages of social responsibility. Santa Clara University. Retrieved from https:// papers.ssrn.com/sol3/papers. cfm?abstract_id $=1372848$

43. Velte, P. (2016) Sustainable management compensation and ESG performance - the German case. Problems and Perspectives in Management, 14(4), 17-24. 